\title{
A Survey on Obesity in Men vs Women
}

\author{
Priyanka Sachdewa and Shubham Mohan Sharma \\ Department of Community Medicine Shree Guru Gobind Singh \\ Tricentary University, Gurugram, Haryana, India \\ Corresponding author email: priyanka1_fmhs@sgtuniversity.org
}

\begin{abstract}
Obesity refers to a state when body fats starts accumulating at a rapid rate and leads to increased risk of diseases such as cardiovascular disease, stroke, high blood pressure, diabetes and sometimes cancer. To control the risk a healthy lifestyle is necessary. The present paper deals with a survey on obesity in order to analyze the obesity in men and women. The survey comprises of 250 participants both male and female categorized into four different groups ranging from 19 years to 65 years. Each participants was provided with a questionnaire comprising set of questions necessary to conduct the survey. The parameters included in conducting the survey include body mass index (BMI), waist to height ratio (WHR), arm circumference and basic knowledge about obesity. The results declared that, women belonging to group 2 and 3 were found to be overweight and women and men belonging to group 4 were found to be obese with BMI greater than 30 and WFR greater than 0.85 for females and greater than 0.90 for males.
\end{abstract}

KEY WORDS: BMI, OBESITY, PARTICIPANTS, SURVEY, WFR.

\section{INTRODUCTION}

In the previous few decades, obesity has been more prevalent, which contributes to high prevalence of diseases. In 2015, there were maximum of 107.7 million obeseglobally(A. Afshin et. al. (2017)). China, an inhabitant developing world with more than 1.3 billion, and largest amount of obese children have seen a rapid rise in obesity(C. Y. Ji (2013), T. O. Cheng (2014)). Thus it is increasingly important in China to counter the problem of childhood obesity. Comportemental and dietary methods play vital part in obesity preventance. A slow intake was suggested for weight management, key principle in behavioural nutrition as satiation regulation was confirmed. For cost-benefit preventative measures, such a basic change in mindset that can impact the person obesity risk is important.

A research study currently included 23 experiments and established that excessive food is related with excess body

Biosc Biotech Res Comm P-ISSN: 0974-6455 E-ISSN: 2321-4007
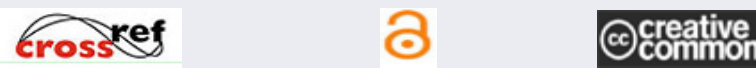

Identifiers and Pagination

Article Information

Year: 2021 Vol: 14 No (6) Special Issue

Received: $13^{\text {th }}$ May 2021

Pages: 425-429 Accepted after revision: $20^{\text {th }}$ July 2021

This is an open access article under Creative

Commons License Attribn 4.0 Intl (CC-BY).

DOI: $h t t p: / / d x . d o i . o r g / 10.21786 / b b r c / 14.7 .89$ wt. in adult populations. In each of the trials the pace of eating was measured utilising the self-reporting form $(22 / 23)$ and total body mass index (BMI) or overall obesity was utilized as an outcome(A. M. Andrade (2008), X. Zeng (2018)). Few other trials have also demonstrated the association between dietary speed and obesity rates. In randomized trial with a small group, disordered eating habits (e.g. quicker eating, overheating) also showed a positive combination of energy and long increase in weight.In current literature, however, differences persist.

Firstly, recent research centered exclusively on a single age category with small studies that did not encourage the possibility to research the disparity with age. Secondly, a research was performed with random populations to explain the connexion between food speed and children's abdominal obesity(X. Zeng (2018), X. Zhang (2020), A. Fogel (2017)). $\mathrm{BMI}$ is probably the most standard indicator of clinical determination of obesity. Practice, but does not differentiate between lean mass and fat mass. The present paper deals with a survey conducted to analyzed the percentage of obesity in men and women and further analyze the conditions responsible for their being obese. This was done in order to analyze the factors responsible for obesity and address the solution for it.

Review Of Literature: Many surveys have been conducted to on obesity. A survey was conducted in South Africa by 
ThandiPuoane and colleagues on obesity comprising both males and females. They focused on Body mass index and waiste to height ratio. Their objective was to ascertain the anthropometric profile anddeterminants of obesity in South Africans who participatedin the Demographic and Health Survey(T. Puoane et. al. (2002)). It was concluded that, both the females and males were found to be obese and the reason was overnutrition.

\section{Research Question}

$1 . \quad$ What is obesity?

2. Who is more prone to obesity, men or women?

3. How to prevent obesity?

\section{METHODOLOGY}

Design: The survey design involves contestants categorized into different groups. The groups were made according to differing age group. The participants were both male and female. There were two groups comprising both men and women, which were further categorized into sub-groups according to age factor (Table 1). Very old people and pregnant ladies and those in wheelchair were excluded from the survey as they may face difficulty in standing straight while measuring the parameters regarding the survey. Trainings were provided to the members for conducting the survey. The questionnaire was prepared and handed over to the participants. The response provided by them was collected and were further analyzed to conclude the results(K. M. Flegal et. al. (2016)). The members involved in the survey were given strict training regarding how to measure Body Mass Index (BMI), height, weight, circumference of arms, waist and alike. They were also taught about how to handle the team in order to achieve a successful survey. This was done so in order to accomplish the task very easily without causing any inconvenience to the participants.

Weight was measured by using calibrated scales. The parameters decided for measuring weight was that the participant should wear clothes but should not wear shoes, or any kind of footwear. Moreover, the participant should also be empty stomach. Height was also measured by employing a stadiometer. These are a medical equipment preferably used for measuring subject height. It is specifically designed comprising a ruler and sliding horizontal headpiece that is adjustable in nature and is rested on the head of the subject to measure the height of the person. The parameters selected for measuring height was that the person should stand barefoot on the stand of the stadiometer with straight back. The circumference of the arm, waist, and hip was measured by using a measuring builders tape whose one end is fixed in the enclosure and other end is flexible i.e. when it is stretched out it gives accurate measure of the arm and the waist.

Sample: A questionnaire was designed comprising all the relevant details regarding obesity. The questions were related to the daily routine of the participants, like what is their eating habits, Body mass index (BMI), perception of each participant was also asked regarding their weight and alike. The response provided by them was further analyzed by a trained group of members and the conclusion was made regarding that. In total there were 200 members who participated in the survey. There were four groups each group comprising 20 members each.

Table 1. Classification of Participants on the Basis of Gender and Age for Conducting Survey on Obesity

\begin{tabular}{|c|c|c|c|}
\hline \multirow{2}{*}{ Group } & \multicolumn{3}{|c|}{ Sample } \\
\cline { 2 - 4 } & Age & Men & Women \\
\hline Group 1 & $15-25$ & $\checkmark$ & $\checkmark$ \\
\hline Group 2 & $26-40$ & $\checkmark$ & $\checkmark$ \\
\hline Group 3 & $41-60$ & $\checkmark$ & $\checkmark$ \\
\hline Group 4 & $61-80$ & $\checkmark$ & $\checkmark$ \\
\hline
\end{tabular}

Table 2. Questionnaire involved for conducting survey

\begin{tabular}{|l|l|}
\hline S.No. & QUESTIONS \\
\hline 1. & Height \\
\hline 2. & Weight \\
\hline 3. & Body mass index (BMI) \\
\hline 4. & Arm Circumference \\
\hline 5. & Waist circumference \\
\hline 6. & Hip circumference \\
\hline 7. & Waist/hip circumference \\
\hline 8. & $\begin{array}{l}\text { Does anyone in your family have } \\
\text { obesity problem? }\end{array}$ \\
\hline 9. & Do you consume junk food? \\
\hline 10. & $\begin{array}{l}\text { Are you involved in consumption } \\
\text { of illicit drugs? }\end{array}$ \\
\hline 11. & Are you diabetic? \\
\hline 12. & What do you mean by obesity? \\
\hline
\end{tabular}

Instrument: The survey was conducted by providing the questionnaire and analyzing the response generated by the respondents or participants. The questionnaire comprises of sets of questions that were crucial for screening the obesity. In total, the questionnaire comprises of 12 questions with relevant options. In some case the options were not provided if a review of the participant is required. The questionnaire involved herein are represented in Table 2.

Table 3. Height measurement of the participants. The height is measured in meters.

\begin{tabular}{|l|c|c|}
\hline \multirow{2}{*}{} & \multicolumn{2}{|c|}{ Samples } \\
\cline { 2 - 3 } & Men & Women \\
\hline \multirow{2}{*}{ GROUP 1 } & 1.70 & 1.63 \\
\hline GROUP 2 & 1.75 & 1.67 \\
\hline GROUP 3 & 1.75 & 1.65 \\
\hline GROUP 4 & 1.65 & 1.59 \\
\hline
\end{tabular}


Data Collection: The response provided by the respondents about the questions asked in the questionnaire is represented in the Table 3-14.

1. Height: Height was measured in meters.

2. Weight: Weight was measured in kgs.

Table 4. Weight measurement of the participants. The weight is measured in kilograms.

\begin{tabular}{|c|c|c|}
\hline \multirow{2}{*}{} & \multicolumn{2}{|c|}{ Samples } \\
\cline { 2 - 3 } & Men & Women \\
\hline \multirow{2}{*}{ GROUP 1 } & 59.5 & 58.0 \\
\hline GROUP 2 & 67.5 & 69.8 \\
\hline GROUP 3 & 69.5 & 72.6 \\
\hline GROUP 4 & 71.2 & 73.5 \\
\hline
\end{tabular}

3. Body Mass Index (BMI): It is a measure of body fat on the basis of subject's height and weight. The subject include both male and female.

Table 5. Body Mass Index (BMI) measurement of the participants. The BMI is measured in kilograms $/ \mathrm{m}^{2}$.

\begin{tabular}{|c|c|c|}
\hline \multirow{2}{*}{} & \multicolumn{2}{|c|}{ Samples } \\
\cline { 2 - 3 } & Men & Women \\
\hline GROUP 1 & 21.2 & 21.9 \\
\hline GROUP 2 & 22.6 & 25.6 \\
\hline GROUP 3 & 22.6 & 27.5 \\
\hline GROUP 4 & 26.9 & 30 \\
\hline
\end{tabular}

4. Arm circumference

Table 6: Arm circumference measurement of the participants. The arm circumference of the upper arm is measured in cm.

\begin{tabular}{|c|c|c|}
\hline \multirow{2}{*}{} & \multicolumn{2}{|c|}{ Samples } \\
\cline { 2 - 3 } & Men & Women \\
\hline \multirow{2}{*}{ GROUP 1 } & 28 & 25.5 \\
\hline GROUP 2 & 29.5 & 31.5 \\
\hline GROUP 3 & 30.8 & 32.5 \\
\hline GROUP 4 & 30.7 & 32.7 \\
\hline
\end{tabular}

9. Do you consume junk food?

10. Are you involved in consumption of illicit drugs?

11. Are you diabetic?

12. What do you mean by obesity?

\section{RESULTS AND DISCUSSION}

All the participants actively participated in the survey. The survey conductors also carried out survey very well and were satisfied with the participant's co-operation. Both the participants and survey conductors were satisfied with each
5. Waist circumference

Table 7. Waist circumference measurement of the participants. The waist circumference of the upper arm is measured in $\mathrm{cm}$.

\begin{tabular}{|c|c|c|}
\hline \multirow{2}{*}{} & \multicolumn{2}{|c|}{ Samples } \\
\cline { 2 - 3 } & Men & Women \\
\hline \multirow{2}{*}{ GROUP 1 } & 71.12 & 64.7 \\
\hline GROUP 2 & 74.93 & 86 \\
\hline GROUP 3 & 78.23 & 86.9 \\
\hline GROUP 4 & 88.17 & 86 \\
\hline
\end{tabular}

\section{Hip circumference}

Table 8. Hip circumference measurement of the participants. The Hip circumference of the upper arm is measured in cm.

\begin{tabular}{|c|c|c|}
\hline \multirow{2}{*}{} & \multicolumn{2}{|c|}{ Samples } \\
\cline { 2 - 3 } & Men & Women \\
\hline \multirow{2}{*}{ GROUP 1 } & 89.9 & 97.5 \\
\hline GROUP 2 & 95.4 & 101 \\
\hline GROUP 3 & 96.5 & 101 \\
\hline GROUP 4 & 96.9 & 98 \\
\hline
\end{tabular}

7. Waist/Hip circumference Ratio

Table 9. Waist/Hip circumference

Ratio measurement of the participants.

\begin{tabular}{|l|c|c|}
\hline \multirow{2}{*}{} & \multicolumn{2}{|c|}{ Samples } \\
\cline { 2 - 3 } & Men & Women \\
\hline \multirow{2}{*}{ GROUP 1 } & 0.79 & 0.66 \\
\hline GROUP 2 & 0.78 & 0.85 \\
\hline GROUP 3 & 0.81 & 0.86 \\
\hline GROUP 4 & 0.90 & 0.87 \\
\hline
\end{tabular}

8. Does anyone in your family have obesity problem?

Table 10: Data regarding family history. From the data it was observed that from the participant one group of women were having family history related to obesity.

\begin{tabular}{|c|c|c|c|c|}
\hline \multirow{2}{*}{} & \multicolumn{2}{|c|}{ Men } & \multicolumn{2}{c|}{ Women } \\
\hline & Yes & No & Yes & No \\
\hline \multirow{2}{*}{ GROUP 1 } & & $\checkmark$ & & $\checkmark$ \\
\hline GROUP 2 & & $\checkmark$ & $\checkmark$ & $\checkmark$ \\
\hline GROUP 3 & & $\checkmark$ & & $\checkmark$ \\
\hline GROUP 4 & & $\checkmark$ & & $\checkmark$ \\
\hline
\end{tabular}


other. After analyzing the result it was concluded that, body mass index of some participants lied in a normal while some participants were found to be overweight. Body mass Index (BMI) refers to a measure of fat on the basis of person's height and weight. The person referred herein include both male and female(J. S. Markowitz et. al. (2018)). The BMI is classified into certain categories that decides whether the person can be categorized as obese or not. The classes are as follows (Table 15).

Table 11. Data regarding junk food consumption. A common data of both men and womenis represented. From the data it can be observed that, group 1 consume junk food at maximum rate while group 4 consume junk food at least rate.

\begin{tabular}{|c|c|c|c|c|}
\hline & Yes & No & Never & Sometimes \\
\hline GROUP 1 & $99 \%$ & $1 \%$ & - & $0 \%$ \\
\hline GROUP 2 & $65 \%$ & $0 \%$ & - & $35 \%$ \\
\hline GROUP 3 & $40 \%$ & $20 \%$ & - & $30 \%$ \\
\hline GROUP 4 & $0 \%$ & $95 \%$ & - & $5 \%$ \\
\hline
\end{tabular}

Table 12. Data regarding illicit drug consumption. A common data of both men and women is represented. From the data it can be observed that, group 1 consume illicit drugs at maximum rate while group 4 consume at least rate.

\begin{tabular}{|c|c|c|c|c|}
\hline & Yes & No & Never & Sometimes \\
\hline GROUP 1 & $99 \%$ & $1 \%$ & - & - \\
\hline GROUP 2 & $65 \%$ & $0 \%$ & - & $35 \%$ \\
\hline GROUP 3 & $40 \%$ & $20 \%$ & - & $30 \%$ \\
\hline GROUP 4 & $0 \%$ & $95 \%$ & - & $5 \%$ \\
\hline
\end{tabular}

Table 13. Data regarding diabetes. A common data of both men and women is represented. From the data it can be observed that, group 4 was more diabetic and group 1 is least diabetic.

\begin{tabular}{|l|c|c|}
\hline & YES & NO \\
\hline GROUP 1 & $5 \%$ & $95 \%$ \\
\hline GROUP 2 & $10 \%$ & $90 \%$ \\
\hline GROUP 3 & $40 \%$ & $20 \%$ \\
\hline GROUP 4 & $70 \%$ & $20 \%$ \\
\hline
\end{tabular}

From the data collected it was observed that, BMI of men and women in group 1 is $21.2 \mathrm{Kg} / \mathrm{m} 2$ and $21.9 \mathrm{Kg} / \mathrm{m} 2$ respectively. From group 2, BMI of men and women is $22.6 \mathrm{Kg} / \mathrm{m} 2$ and $25.6 \mathrm{Kg} / \mathrm{m} 2$. From group 3, BMI of men and women is $22.6 \mathrm{Kg} / \mathrm{m} 2$ and $27.5 \mathrm{Kg} / \mathrm{m} 2$ respectively. From group 4, BMI was $26.9 \mathrm{Kg} / \mathrm{m} 2$ and $29.6 \mathrm{Kg} / \mathrm{m} 2$ of men and women respectively. From the data it is observed that, BMI of women states that they fall in category of obesity and thus are obese. Women belonging to group
2 and 3 are overweight and group 4 women are found to be obese. The reason for women obesity may be lack of exercise, emotional thinking, and change in hormone level Oestrogen. The increased level of oestrogen causes cellulite, water retention, excess weight in hip and thigh along with increased breast size. Another hormone is cortisol which controls the stress level of women. If the women takes excessive stress then production of cortisol leads to accumulation of fats around internal organs which leads to excessive belly fats.

Table 14. Data regarding participant's knowledge. It was observed that all the participants were aware about obesity.

\begin{tabular}{|c|c|}
\hline & Response \\
\hline GROUP 1 & $\begin{array}{l}\text { A serious health condition, wherein extra } \\
\text { fat gets accumulated that leads to serious } \\
\text { health issues. }\end{array}$ \\
\hline GROUP 2 & $\begin{array}{l}\text { A state where body starts gaining fat in } \\
\text { excessive amount and person starts becoming } \\
\text { prone to fat. }\end{array}$ \\
\hline GROUP 3 & $\begin{array}{l}\text { A condition where body starts gaining weight } \\
\text { in such a great amount that it becomes very } \\
\text { difficult to control it and chances of } \\
\text { cardiovascular disease starts increasing. }\end{array}$ \\
\hline GROUP 4 & $\begin{array}{l}\text { A serious health condition, wherein } \\
\text { extra fat starts developing in body } \\
\text { and person starts gaining weight and } \\
\text { feels so lazy and dizzy. }\end{array}$ \\
\hline
\end{tabular}

Table 15. Standard representation of weight category according to Body Mass Index (BMI)

\begin{tabular}{|l|c|}
\hline Classes & Categories \\
\hline Underweight & $<18.5$ \\
\hline Normal & $18.5-24.9$ \\
\hline overweight & $25-29.9$ \\
\hline Obese & BMI of 30 or greater \\
\hline
\end{tabular}

Similarly, waist/hip ratio is also a category of obesity measurement. According to $\mathrm{WHO}$, weight to Height ratio i.e. WHR is an important parameter for obesity measurement. WHR varies differently in men and women. In men, WHR of male is greater than 0.90 and for female WHR is greater than 0.85 . From the data collected, WHR of men and women in group 1 is 0.79 and 0.66 respectively which states that, they are not obese. In group 2, WHR of men and women is 0.78 and 0.85 respectively which indicates that, women are more prone of be obese while men are safe. In group 3 , it is observed that, WHR of men is 0.81 and WHR of women is 0.86 which indicates that, women are obese. In group 4 , it is observed that, WHR of men is 0.90 and WHR of women is 0.87 which clearly indicates that both of them are obese. The women with WHR of 0.86 and above are 
high rate of obese. Similarly, men with WHR of 0.90 are lower rate of obese.

From the data of arm circumference it is observed that, arm circumference was fine of both men and women. Also in knowledge testing about obesity it was observed that, all the groups were aware of this condition. From the data collected and analyzed it was concluded that women are more prone to obesity as compared to men. The reason behind this can be many starting from poor diet, stress, emotional attacks, unbalanced sleep, slower metabolism, pregnancy, hormonal changes and alike. Thus it is advisable that, women should take care of their health and should adopt a balanced diet.

\section{CONCLUSION}

Obesity is not a problem that can be neglected. It is a medical issue that worsen the condition by exposing the person to chronic diseases such as cardiovascular diseases, high blood pressure, diabetes, and cancers. From the survey conducted it was analyzed that, participants belonging to group 2 and 3 , only women were found to be overweight while men were not. However, women in group 4 were found to be obese and men were moderately prone to obesity. Thus it can be concluded that, necessary steps should be taken to prevent obesity, like regular exercise should be included in lifestyle, a healthy diet should be included, continuous monitoring should be there and meditation should be done before going to bed in order to have stress free and a healthy mind.

\section{REFERENCES}

Andrade, A.M., Greene, G.W. and Melanson, K.J., 2008. Eating slowly led to decreases in energy intake within meals in healthy women. Journal of the American Dietetic Association, 108(7), pp.1186-1191.

Cheng, T.O., 2014. China's epidemic of child obesity:: An ounce of prevention is better than a pound of treatment. International journal of cardiology, 172(1), pp.1-7.
Fogel, A., Goh, A.T., Fries, L.R., Sadananthan, S.A., Velan, S.S., Michael, N., Tint, M.T., Fortier, M.V., Chan, M.J., Toh, J.Y. and Chong, Y.S., 2017. Faster eating rates are associated with higher energy intakes during an ad libitum meal, higher BMI and greater adiposity among 4- 5-year-old children: Results from the Growing Up in Singapore Towards Healthy Outcomes (GUSTO) cohort. British Journal of Nutrition, 117(7), pp.1042-1051.

Khader, H., 2017. A FIRST IMAGE OF THE LORD OF WORDS.

Ji, C.Y. and Chen, T.J., 2013. Working Group on Obesity in China (WGOC) Empirical changes in the prevalence of overweight and obesity among Chinese students from 1985 to 2010 and corresponding preventive strategies. Biomed Environ Sci, 26(1), pp.1-12.

Markowitz, J.S., 2018. Body mass index (BMI). In Mortality and Its Risk Factors Among Professional Athletes (pp. 39-49). Springer, Cham.

Ogden, C.L., Carroll, M.D., Lawman, H.G., Fryar, C.D., Kruszon-Moran, D., Kit, B.K. and Flegal, K.M., 2016. Trends in obesity prevalence among children and adolescents in the United States, 1988-1994 through 20132014. Jama, 315(21), pp.2292-2299.

Puoane, T., 2002. Steyn K, Bradshaw D, Laubscher R, Fourie J, Lambert V, Mbananga N. Obesity in South Africa: the South African demographic and health survey. Obes Res, 10, pp.1038-1048.

Zhang, X., Zhang, M., Zhao, Z., Huang, Z., Deng, Q., Li, Y., Pan, A., Li, C., Chen, Z., Zhou, M. and Yu, C., 2020. Obesogenic environmental factors of adult obesity in China: a nationally representative cross-sectional study. Environmental Research Letters, 15(4), p.044009.

Zeng, X., Cai, L., Ma, J., Ma, Y., Jing, J. and Chen, Y., 2018. Eating fast is positively associated with general and abdominal obesity among Chinese children: A national survey. Scientific reports, $8(1)$, pp.1-8. 